Article

\title{
Candida albicans Morphology-Dependent Host FGF-2 Response as a Potential Therapeutic Target
}

\author{
Sandeep Vellanki, Eun Young Huh, Stephen P. Saville and Soo Chan Lee * \\ South Texas Center for Emerging Infectious Diseases (STCEID), Department of Biology, \\ The University of Texas at San Antonio, San Antonio, TX 78249, USA; sandeep.vellanki@my.utsa.edu (S.V.); \\ eunyoung.huh@utsa.edu (E.Y.H.); stephen.saville@utsa.edu (S.P.S.) \\ * Correspondence: soochan.lee@utsa.edu; Tel.: +1-(210)-458-5398
}

Received: 10 January 2019; Accepted: 1 March 2019; Published: 5 March 2019

\begin{abstract}
Angiogenesis mediated by proteins such as Fibroblast Growth Factor-2 (FGF-2) is a vital component of normal physiological processes and has also been implicated in contributing to the disease state associated with various microbial infections. Previous studies by our group and others have shown that Candida albicans, a common agent of candidiasis, induces FGF-2 secretion in vitro and angiogenesis in brains and kidneys during systemic infections. However, the underlying mechanism(s) via which the fungus increases FGF-2 production and the role(s) that FGF-2/angiogenesis plays in C. albicans disease remain unknown. Here we show, for the first time, that $C$. albicans hyphae (and not yeast cells) increase the FGF-2 response in human endothelial cells. Moreover, Candidalysin, a toxin secreted exclusively by C. albicans in the hyphal state, is required to induce this response. Our in vivo studies show that in the systemic C. albicans infection model, mice treated with FGF-2 exhibit significantly higher mortality rates when compared to untreated mice not given the angiogenic growth factor. Even treatment with fluconazole could not fully rescue infected animals that were administered FGF-2. Our data suggest that the increase of FGF-2 production/angiogenesis induced by Candidalysin contributes to the pathogenicity of C. albicans.
\end{abstract}

Keywords: angiogenesis; FGF-2; morphogenesis; Candidalysin

\section{Introduction}

Candida albicans is a commensal/opportunistic fungal pathogen most commonly associated with mucosal diseases in humans. Lethal infections by $C$. albicans are continuously increasing in parallel with the growing proportion of vulnerable individuals such as immunocompromised patients and/or patients with indwelling medical devices [1-3]. In particular, disseminated infections pose a serious threat as mortality rates can exceed $40 \%$ even when patients receive antifungal therapy [4].

Many of the antifungal drugs that are currently used in clinical practice target fungal cells by inhibiting their growth or by killing them; they include azoles (targeting ergosterol synthesis), polyenes (physiochemically targeting ergosterol), and echinocandins (targeting cell wall synthesis) [5]. However, like many other microbial pathogens, C. albicans can develop resistance against antifungal drugs via (1) mutations in drug target genes, (2) up-regulation of multidrug resistance genes, or (3) the Hsp90-mediated stress response pathway [6,7]. Indeed, many clinical C. albicans isolates are multidrug resistant, and the emergence of drug resistance often leads to poor outcome in the treatment [8]. Therefore, it is imperative to develop novel therapeutic options that are not prone to resistance by the fungus.

Angiogenesis is the development of new blood vessels from pre-existing vessels [9]. It is regulated by proteins that either activate or inhibit the process [10]. Fibroblast Growth Factor-2 (FGF-2) is a pro-angiogenic protein that promotes angiogenesis in an autocrine fashion $[11,12]$. Studies have 
shown that FGF-2 is a more potent inducer of angiogenesis then other pro-angiogenic proteins such as Vascular Endothelial Growth Factor (VEGF) [13]. While modulation of FGF-2 or angiogenesis has become a common target in the treatment of cancer [14-16], studies from Ben-Ami et al. have shown such therapies could potentially be extended to treat fungal infections [17]. When Aspergillus fumigatus infected mice were treated with FGF-2 alone or in combination with antifungals, there was a significant increase in survival rate compared to the untreated group. However, the role of angiogenesis in C. albicans infection and disease progression is understudied.

Ashman et al. have shown that C. albicans increases angiogenesis in a murine model of systemic candidiasis [18]. Our group and others have revealed in vitro that $C$. albicans-mammalian host cell interactions result in increased production of proangiogenic growth factors, including FGF-2, and expression of the gene encoding VEGF [19-21]. However, the underlying molecular mechanisms of how the fungus induces FGF-2/angiogenesis in hosts remain elusive.

This study identifies a fungal factor that modulates host FGF-2 secretion and explores the role of FGF-2 in C. albicans infections. We found that in vitro induction of endothelial cell FGF-2 production is dependent on C. albicans morphology, with an increase in FGF-2 protein secretion only noted when the fungus was present in the filamentous form. Moreover, we determined that Candidalysin, a secreted hypha-specific toxin, regulates this process. Finally, using a murine model of systemic candidiasis, we discovered that treatment of $C$. albicans infected animals with FGF-2 results in increased mortality, suggesting that $C$. albicans induces FGF-2/angiogenesis to enhance pathogenicity.

\section{Materials and Methods}

\subsection{Ethics Statement}

All animal experiments were performed in strict accordance with the guidelines of the University of Texas at San Antonio (UTSA) Institutional Animal Care and Use Committee (IACUC) and in full compliance with the United States Animal Welfare Act (Public Law 98-198) and National Institute of Health guidelines. The animal protocol used in this study was approved by the UTSA IACUC under protocol MU104. The experiments were conducted in the Division of Laboratory Animal Resources (DLAR) facilities that are accredited by the Association for Assessment and Accreditation of Laboratory Animal Care (AAALAC).

\subsection{Cell Culture}

Primary Human Umbilical Vein Endothelial Cells (HUVECs) were purchased from Lonza and were seeded into a T75 flask and maintained at $37^{\circ} \mathrm{C}+5 \% \mathrm{CO}_{2}$ in Endothelial Cell Basal Medium containing hydrocortisone, abscorbic acid, Insulin Growth Factor, heparin, and FBS (EBM; Lonza) according to manufacturer instructions. The components of the HUVEC medium that were not added during the experiments include gentamicin and two proangiogenic growth factors, FGF-2 and VEGF, that are often used to culture HUVEC. Confluent flasks of cells were trypsinized and seeded into a 96-well plate for challenge with C. albicans.

\subsection{Fungal Strains and Growth Conditions}

C. albicans strains were maintained as glycerol stocks at $-80^{\circ} \mathrm{C}$ and were propagated by streaking on yeast-peptone-dextrose (YPD) agar plates as needed. A day before the infection (as explained below), colonies of cells from the plate were transferred to YPD liquid medium and were incubated overnight $(16 \mathrm{~h})$ at $30{ }^{\circ} \mathrm{C}$ with shaking $(180 \mathrm{rpm})$. The yeast cells were then washed with sterile phosphate-buffered saline (PBS), resuspended, and diluted to the desired concentration using sterile PBS. The list of strains used in this study is shown in Table 1. 


\subsection{HUVECs Challenge with C. albicans}

HUVECs were counted and the cell number was adjusted to seed $5 \times 10^{3}$ cells/well in $100 \mu \mathrm{L}$ medium in a 96-well plate. HUVECs were challenged with $5 \times 10^{4}$ cells/well $(\mathrm{MOI}=10 ; 10 \mu \mathrm{L} /$ well in PBS) of each of the C. albicans strains for $24 \mathrm{~h}$. The supernatants were collected from each well and FGF-2 Enzyme Linked Immuno Sorbent Assay (ELISA; R\&D systems) was performed according to the manufacturer's instructions to determine FGF-2 protein levels. When tetracycline-regulatable strains were used, doxycline were added to appropriate wells at a final concentration of $20 \mu \mathrm{g} / \mathrm{mL}$ [22]. For experiments involving compound 9029936 [23], the compound was added to appropriate wells in various concentrations as explained in Section 3.1. All ELISA measurements were performed in at least two independent experiments with three technical repeats.

Table 1. List of strains.

\begin{tabular}{cc}
\hline Strain & Reference \\
\hline SC5314 & {$[24]$} \\
CAN33 $($ efg1 $\Delta / \Delta)$ & {$[25]$} \\
SSY50-B $($ tet-NRG1) & {$[26]$} \\
SN152 & {$[27]$} \\
$17322($ als3 $\Delta / \Delta)$ & {$[28]$} \\
$b c r 1 \Delta / \Delta$ & {$[29]$} \\
BWP17 + CIp30 & {$[30]$} \\
ece1 $1 / \Delta$ & {$[30]$} \\
ece1 $/ \Delta+$ ECE1 & {$[30]$} \\
ece1 $/ \Delta+$ ECE1 $184-279$ & {$[30]$} \\
SAP456MS4A/B $($ Sap4-6 $\Delta / \Delta)$ & {$[31]$} \\
SAP123MS4C/D $($ Sap1-3 $1 / \Delta)$ & {$[31]$} \\
\hline
\end{tabular}

\subsection{HUVECs Challenge with C. albicans Spent Medium}

The concentrations of $C$. albicans strain SC5314 (with or without compound 9029936) and the non-hypha-forming mutant efg $1 \Delta / \Delta$ [29] were adjusted to $5 \times 10^{6} / \mathrm{mL}$, and they were grown for $24 \mathrm{~h}$ in HUVEC cell culture medium (EBM) at $37^{\circ} \mathrm{C}$. The medium was centrifuged at $2500 \times g$ for $15 \mathrm{~min}$ and the supernatant filtered through a sterile $0.22 \mu \mathrm{m}$ filter. The resulting medium was immediately added to HUVECs and incubated for $24 \mathrm{~h}$ before proceeding to the ELISA.

\subsection{HUVECs Challenge with C. albicans Nonviable (Heat-Killed and PFA-Treated) Strains}

Wild-type SC5314 and efg $1 \Delta / \Delta$ mutant strains were resuspended at a final concentration of $5 \times 10^{6} / \mathrm{mL}$ in EBM and incubated at $37^{\circ} \mathrm{C}$ until germination was observed $(\sim 3 \mathrm{~h})$ in the tubes containing the SC5314 strain. As a control, we also incubated both C. albicans strains at $28^{\circ} \mathrm{C}$ (no germ tube control). The vials containing the cells were then subjected to heat $\left(95^{\circ} \mathrm{C}\right)$ for $30 \mathrm{~min}$ [32]. Since heat treatment could alter the cell wall of $C$. albicans, we also included a paraformaldehyde (PFA)-treated group. For the PFA treatment, the fungal cells were incubated in PFA for $30 \mathrm{~min}$ then washed with PBS several times. For the challenge experiment, either $5 \times 10^{4}$ viable or $5 \times 10^{4}$ nonviable (heat-killed or PFA-treated) cells were added to each HUVEC well and incubated for $24 \mathrm{~h}$. Both viable and nonviable C. albicans were also plated on YPD plates to confirm the loss of viability in the heatand PFA-treated groups.

\subsection{HUVECs Challenge with Candidalysin Peptide}

Candidalysin peptide (SIIGIIMGILGNIPQVIQIIMSIVKAFKGNK) [30] was a kind gift from Dr. Julian Naglik (King's College London). The peptide was prepared as a $10 \mathrm{mg} / \mathrm{mL}$ stock in sterile water. Serum-starved HUVECs were seeded in a 96-well plate and incubated with Candidalysin peptide diluted to $9 \mu \mathrm{M}$ in sterile water for $24 \mathrm{~h}$. Supernatants were collected to perform ELISA. 


\subsection{Evaluation of FGF-2 Monotherapy and Combination Therapy with Fluconazole in a Murine Model of Systemic Candidiasis}

Balb/C mice (male, 4-6 weeks old) were purchased from Charles River Laboratories. For $C$. albicans infections, the mice were infected with $1 \times 10^{6}$ SC5314 yeast cells in $100 \mu \mathrm{L}$ sterile PBS via a lateral tail vein. For monotherapy, the infected mice were given $1.6 \mu \mathrm{g}$ of recombinant human FGF-2 (R\&D systems) in $100 \mu \mathrm{L}$ sterile PBS intravenously at 3 and $5 \mathrm{~h}$ after infection, as described previously [17]. For combination therapy, fluconazole was administered daily at $0.5 \mathrm{mg} / \mathrm{kg}$ via the intraperitoneal route starting $5 \mathrm{~h}$ after infection for 7 days. We also included animal groups infected with SC5314 alone or SC5314 treated with fluconazole. Negative controls included non-infected groups given either PBS or rFGF-2 only. Post-infection survival of the mice was monitored twice daily, and body weights were measured once daily (as this is a good indicator of mouse health). Animals which suffered a weight loss of more than $10 \%$ a day or total of $20 \%$ from the initial point were humanely sacrificed. Differences between the survival curves were evaluated for significance using the Kaplan-Meier test. The animals were housed in an SPF room, and after infection they were housed in a BSL2 room. The animals were given free access to food and sterile water. All of the mice in the same cage were part of the same treatment group.

\subsection{Statistics}

Prism (Version 7. GraphPad Software Inc.) was used to perform statistical analysis. A $p$ value of $\leq 0.05$ was considered to be statistically significant. All in vitro experiments were performed in tripicate, and each experiment was performed on at least three separate occasions. Data are expressed as mean \pm SEM. In vivo challenge experiments were performed on two independent occasions with $n=5$ in each group. Two independent experiments showed similar results and the data shown are from one representative experiment.

\section{Results}

\subsection{FGF-2 Protein Secretion from Hosts is Dependent on the Morphology of the C. albicans}

In the current study, HUVECs were challenged with either a wild-type (SC5314), a non-hypha-forming mutant $(e f g 1 \Delta / \Delta)$ (Figure S1), or a regulatable tet-NRG1 strain [26]. Nrg1 is a transcriptional repressor which suppresses the expression of hypha-specific genes in yeast-form cells. The tet-NRG1 strain was constructed by placing one allele of NRG1 under the control of a tetracycline-regulatable promoter so that the morphology could be manipulated by adding or omitting doxycycline (dox) [26]. While the addition of dox permits filamentation, omission results in a yeast-locked morphology. As shown in Figure 1a, compared to the uninfected PBS control (mock), FGF-2 production was significantly higher only when C. albicans was able to filament-in the wild type (WT) and tet-NRG1 (+dox). We did not observe a substantial change in HUVECs challenged with the efg1 $\Delta / \Delta$ and tet-NRG1 (-dox) strains (when C. albicans cells remained in the yeast form). As a control, an ELISA was also performed on supernatants from wells with C. albicans only (no HUVECs); however, as expected, no FGF-2 protein above background could be detected (Figure S2). We also determined that the presence of doxycycline does not influence the FGF-2 response (Figure S3a).

As an alternative approach to test how C. albicans morphology affects FGF-2 production, we challenged HUVEC cultures with the C. albicans WT strain SC5314 in the absence or presence of compound 9029936 for $24 \mathrm{~h}$. Compound 9029936, identifed by Romo et al., blocks C. albicans filamentation and biofilm formation [23]. In agreement with the data presented in Figure 1a, HUVECs responded to untreated C. albicans (hyphae) with increased FGF-2 expression; however, the presence of the drug ( 2.5 to $40 \mu \mathrm{M})$ significantly diminished this effect (Figure 1b). Compound 9029936 by itself does not affect FGF-2 response from HUVECs (Figure S3b). Taken together (Figure 1a,b), these results suggest that the host FGF-2 response is specific to the hyphal form of $C$. albicans. 


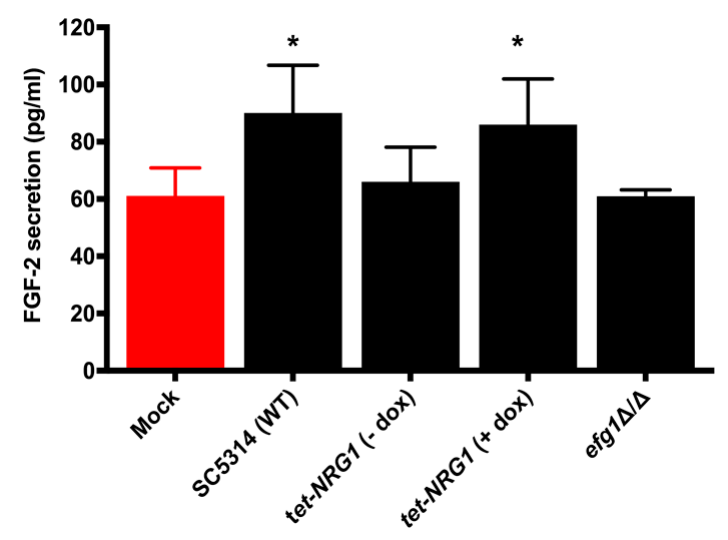

(a)

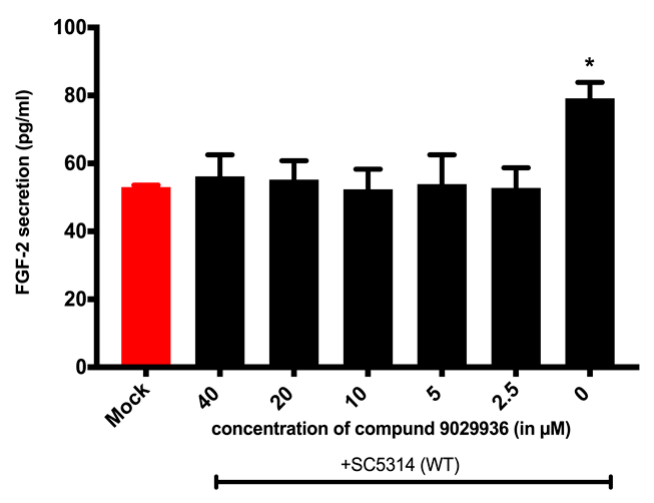

(b)

Figure 1. Host Fibroblast Growth Factor-2 (FGF-2) response is dependent on the morphology of C. albicans. (a) Human Umbilical Vein Endothelial Cells (HUVECs) were challenged with SC5314 (wild-type, WT), tet-NRG1 (+/ - dox), or efg1 $\triangle / \triangle$ strains for 24 h. FGF-2 levels were measured using ELISA. One-way ANOVA was significant $(p=0.0005)$. Dunnett's multiple comparison was used to compare each infected group with the uninfected group (mock). A $p$ value of $<0.05$ was considered to be significant, as indicated by $\left({ }^{*}\right)$. (b) HUVECs were challenged with the wild-type strain SC5314 in the presence ( 40 to $2.5 \mu \mathrm{M}$ ) or absence $(0 \mu \mathrm{M})$ of compound 9029936 for $24 \mathrm{~h}$, and the amount of FGF-2 measured in the supernatants. One-way ANOVA was significant $(p=0.042)$. Dunnett's multiple comparison test demonstrated a statistically significant difference $\left({ }^{*} p<0.05\right)$ only between the Mock group and the infected group without compound 9029936 treatment $(0 \mu \mathrm{M})$.

\subsection{Viable C. albicans Hyphae are Required for the Induction of the FGF-2 Response}

We next determined whether the FGF-2 production/induction is dependent on the viability of the fungal cells. To that end, C. albicans WT (SC5314) were allowed to germinate by incubating at $37^{\circ} \mathrm{C}$ in EBM, and then the hyphae were heat-inactivated or PFA-treated (nonviable) and added to HUVEC-containing wells for $24 \mathrm{~h}$. As shown in Figure 2, while live (no heat or PFA treatment) C. albicans hyphae were able to induce significant FGF-2 protein production, HUVECs challenged with nonviable $C$. albicans hyphae do not display this phenomenon when compared to untreated controls (mock). We also did not observe any difference in FGF-2 secretion between HUVECs challenged with nonviable WT and those challenged with viable/nonviable efg $1 \Delta / \Delta$. The control group which was incubated at $28^{\circ} \mathrm{C}$ did not any show any germ tube formation. When the live counterparts of this group were added to HUVECs and incubated at $37^{\circ} \mathrm{C}$ for $24 \mathrm{~h}$, as expected, they switched to hyphal growth and induced a significant increase in FGF-2 secretion when compared to their heat-killed and PFA-treated counterparts (which cannot make hyphae due to a lack of viability). These results suggest that a factor produced from live C. albicans hyphae is required to elicit an FGF-2 response.

Once it was confirmed that $C$. albicans hyphae were required to elicit an FGF-2 host response, we wanted to test if hyphal-cell-wall-associated proteins are involved in this process. Als3-a member of the agglutinin-like sequence (Als) family of proteins-expressed on the hyphal surface is required for C. albicans adhesion and invasion of epithelial and endothelial cells [33]. Bcr1 is a transcriptional regulator of several hyphal cell wall proteins, including the Als3 invasin [34]. We tested als $3 \Delta / \Delta$ and $b c r 1 \Delta / \Delta$ strains for their ability to induce FGF-2 production, but we observed no significant change when compared to their respective parental strains (Figure S4). We also tested the possible role of secreted aspartyl proteases (Saps; suggested to play a role in C. albicans virulence) in modulating the host FGF-2 response. To that end, HUVECs were challenged with mutant strains lacking either the Saps 1-3 or 4-6 subfamilies or with the WT strain; however, deletion of the Sap subfamilies did not impact FGF-2 production from HUVECs in a 24-hour period (Figure S5). 


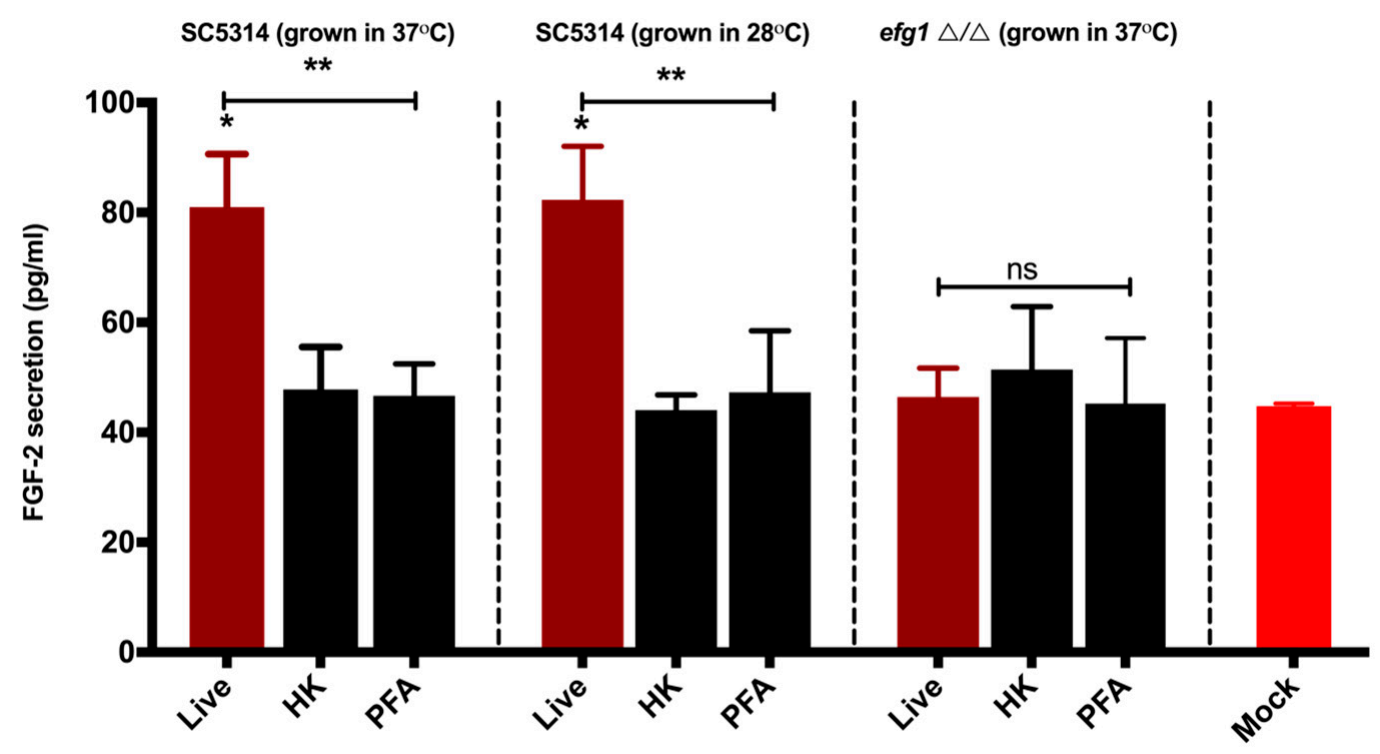

Figure 2. A factor(s) from viable C. albicans hyphae regulates the host FGF-2 response. C. albicans SC5314 (WT) strain was grown in Endothelial Cell Basal Medium (EBM) at $37^{\circ} \mathrm{C}$ until germ tubes were visible ( $\sim 3 \mathrm{~h}$ ). Controls were SC5314 grown at $28^{\circ} \mathrm{C}$ and the $e f g 1 \triangle / \triangle$ mutant at $37^{\circ} \mathrm{C}$ for the same time period (during which no germ tubes were detected). Each group was split into three subgroups: no treatment (live) or treatment with heat (HK) or paraformaldehyde (PFA). HUVECs were challenged with live, HK-, or PFA-treated C. albicans and were maintained at $37{ }^{\circ} \mathrm{C}$ for $24 \mathrm{~h}$. FGF-2 levels in the culture supernatants were measured by ELISA. Both one-way ANOVA $(p=0.009)$ and Dunnett's multiple comparison test $(p<0.05)$ showed statistically significant differences between the Mock and SC5314 live groups (as indicated by *). There was also a statistically significant difference between the live and nonviable groups (HK and PFA) in SC5314 groups (as indicated by ** for $p<0.05$ ).

\subsection{Candidalysin Induces Host FGF-2 Protein Secretion}

Candidalysin, encoded by the ECE1 gene, is a 32-amino-acid peptide, with its dominant form being a 31-amino-acid peptide after cleavage by Kex1p [35], and was the first cytolytic toxin identified in C. albicans [30]. Since Candidalysin is a hypha-specific toxin and was found to be a key factor involved in activating specific host responses, we decided to test if Candidalysin also regulates the host FGF-2 response. We used several ECE1 gene-modified strains to evaluate the relationship between Candidalysin and the host FGF-2 response. HUVECs were challenged with a C. albicans ECE1-null mutant in which both copies of the gene were deleted (ece1 $\Delta / \Delta)$, or with a strain in which one copy of a full-length allele of ECE1 was restored (ece1 $\Delta / \Delta+E C E 1)$, or the strain lacking the region of ECE1 that encodes Candidalysin (ece1 $\Delta / \Delta+E C E 1_{\Delta 184-279)}$, or the wild-type parental strain (BWP17 + CIp30) for $24 \mathrm{~h}$. As shown in Figure $3 \mathrm{a}$, while the ece1 $\Delta / \Delta$ mutant and the ece1 $\Delta / \Delta+E C E 1_{\Delta 184-279}$ strain failed to cause a substantial increase in FGF-2 secretion, the parental and reconstituted ece1 $1 \Delta / \Delta+E C E 1$ strains induced a significant increase when compared to the uninfected control (mock).

To verify that Candidalysin is the mediator of the FGF-2 response, we challenged HUVECs with the Candidalysin peptide and, as shown in Figure $3 b$, addition of the peptide alone was sufficient to induce a significant increase in FGF-2 secretion when compared to the untreated vehicle control (sterile water). Thus, the findings from Figure $3 \mathrm{a}, \mathrm{b}$ confirm that Candidalysin induces secretion of FGF-2 from endothelial cells. On the other hand, it is unlikely that the host FGF-2 induces the expression of Candidalysin as wild-type SC5314 did not exhibit hyphal growth when cultured in the presence of recombinant FGF-2 (rFGF-2) (data not shown).

To determine if the spent medium from C. albicans is sufficient to induce FGF-2 secretion, the C. albicans efg $1 \Delta / \Delta$ mutant and the SC5314 wild-type strain (with or without $10 \mu \mathrm{M}$ compound 9029936) were grown in EBM for $24 \mathrm{~h}$. The medium was filtered, then added to HUVECs and incubated for 
$24 \mathrm{~h}$. However, we did not observe a significant difference in FGF-2 production among the groups (Figure S6).

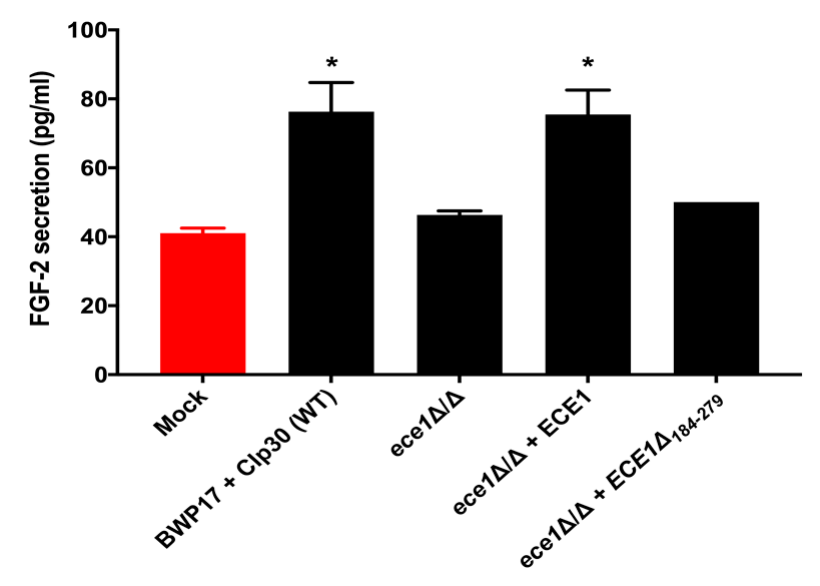

(a)

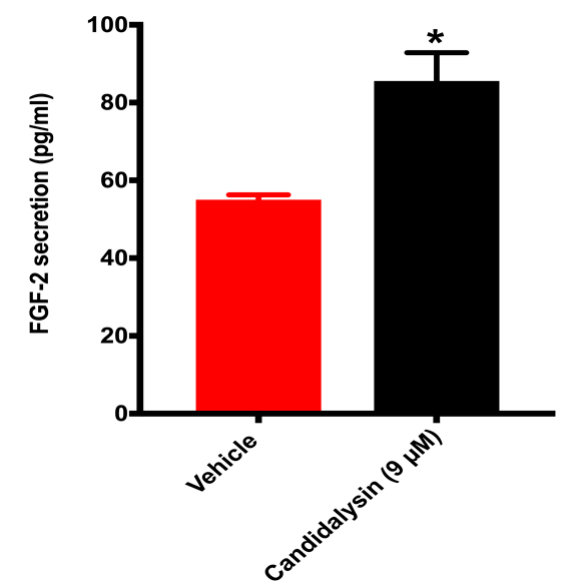

(b)

Figure 3. Candidalysin regulates the host endothelial FGF-2 response. (a) HUVECs were challenged with BWP17 + CIp30 (WT), ece1 $\triangle / \triangle$, ece1 $\triangle / \triangle+E C E 1$, or ece1 $\triangle / \triangle+E C E 1 \triangle 184-279$ for 24 h. FGF-2 levels were measured using ELISA. One-way ANOVA was significant $(p=0.001)$. Dunnett's multiple comparison demonstrated that compared to the uninfected group (Mock), only HUVECs challenged with BWP17 + CIp30 or ece1 $\triangle / \triangle+$ ECE1 showed a statistically significant increase in the FGF-2 response $(p<0.05)$, as indicated by $\left(^{*}\right)$. (b) HUVECs were treated with vehicle control (water) or Candidalysin peptide for $24 \mathrm{~h}$. A two-tailed $t$-test showed a statistically significant difference between the two groups $(p=0.049)$, indicated as $\left(^{*}\right)$.

\subsection{FGF-2 Enhances Mortality Rate in a Murine Model of Systemic Candidiasis}

To evaluate the role of FGF-2/angiogenesis in systemic candidiasis, we infected mice with the wild-type strain SC5314 via a lateral tail vein either alone or in addition to two FGF-2 (1.6 $\mu \mathrm{g})$ treatments (at $3 \mathrm{~h}$ and $5 \mathrm{~h}$ post-infection). The other treatment groups were infection + fluconazole $(0.5 \mathrm{mg} / \mathrm{kg})$ treatment for seven days or infection + a combination of fluconazole and FGF-2. The infected group treated with FGF-2 showed a significant increase in the mortality rate, which is evident from all mice reaching death by Day 6, compared to the no-treatment group, in which the animals start succumbing from Day 6 onwards (Figure 4). Interestingly, co-treating the infected mice with both FGF-2 and fluconazole resulted in increased mortality rates when compared to the infected mice group treated with fluconazole alone. Once the fluconazole treatment was stopped, we observed a decreased survival rate from $100 \%$ to $80 \%$ on Day 12 in WT + fluconazole group (not shown in figure). Treatment of uninfected mice with PBS or FGF-2 did not have any impact on the mortality (survival rates) or morbidity (body weights) of the animals, indicating that administration of FGF-2 is only detrimental in the presence of an active $C$. albicans infection. 


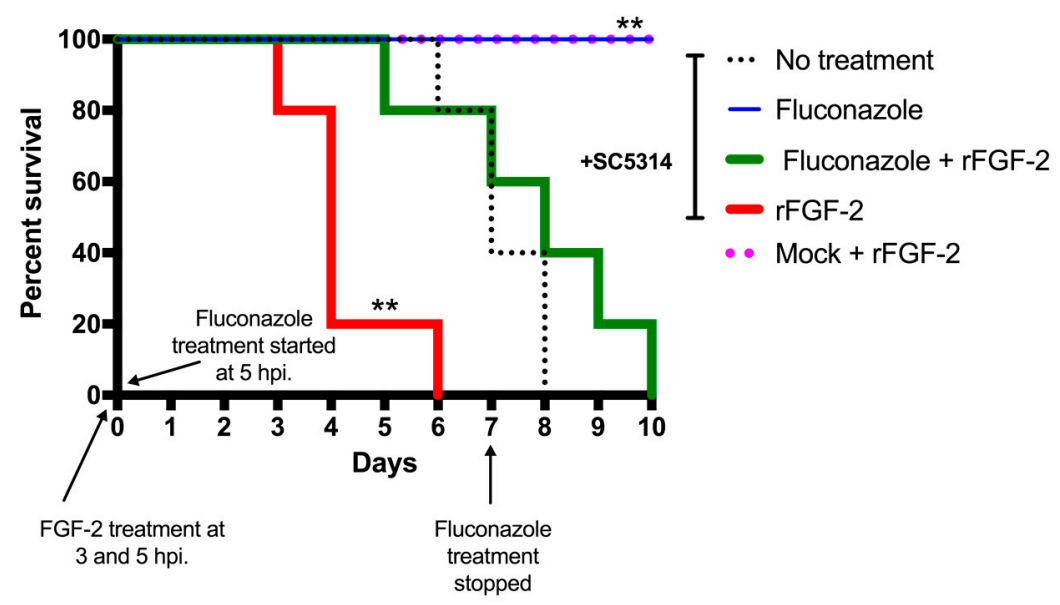

Figure 4. Treatment with FGF-2 increases the mortality rate in a murine model of systemic candidiasis. Balb/C mice were challenged with $1 \times 10^{6}$ SC5314 yeast cells via a tail vein. Fluconazole $(0.5 \mathrm{mg} / \mathrm{kg})$ was administered daily via the intraperitoneal (IP) route from the day of infection for 7 days in the respective animal groups. Recombinant FGF-2 (1.6 $\mu \mathrm{g}$ each dose/mouse) was administered intravenously in the respective groups (infected and uninfected) $3 \mathrm{~h}$ and $5 \mathrm{~h}$ post-infection (hpi). A log-rank (Mantel-Cox) test was statistically significant $(p<0.0001)$. A pair-wise comparison was also performed to compare the following infected groups: no treatment vs. $\operatorname{rFGF}-2\left({ }^{* *} p=0.006\right)$, no treatment vs. rFGF-2 + Fluconazole $(p=0.291)$, and no treatment vs. Fluconazole $(* * p=0.002)$, as indicated on the graph. Once the fluconazole treatment was stopped, the survival rate of the Fluconazole group changed to $80 \%$ (with the death of 1 of the mice) on Day 12 post-infection (not shown on graph). Mice injected with only PBS and rFGF-2 maintained a 100\% survival rate.

\section{Discussion}

Understanding host-pathogen interactions provides a fundamental platform for the development of new therapeutic interventions. Our previous studies revealed an intriguing outcome of the host-pathogen interaction: the induction of the pro-angiogenic growth factor FGF-2 in mammalian hosts by fungal pathogens, including C. albicans $[19,20]$. Our findings are congruent with the study by Ashman et al. where they observed an increase in angiogenesis, characterized by enhanced endothelial cell proliferation including formations of capillary buds and small blood vessels in brain and kidney sections, in a murine model of systemic candidiasis [18]. However, the underlying mechanisms of the C. albicans-host FGF-2/angiogenesis response has not yet been fully explored.

C. albicans can grow in several different morphologies and it is the switch from the yeast to hyphal form which is most closely linked to its capacity to cause disease. During pathogenesis, while the yeast morphology is essential for colonization and dissemination through the bloodstream, the hyphal form is required for invasion and damage to host tissues [36,37]. During host-C. albicans interactions, the host response has been shown to vary depending on the morphological form of the fungus [38-40]. This prompted us to test whether the induction of host FGF-2 secretion is also linked with a particular morphological form of $C$. albicans. To this end, we used HUVECs because they recapitulate the features of endothelial cells lining the lumen of blood vessels [41]. Moreover, HUVECs have already been extensively used to characterize the endothelial cell FGF-2 response [42] and to investigate C. albicans-endothelial cell interactions [43-46]. As the results in Figure 1a,b show, C. albicans can induce FGF-2 secretion only in the hyphal form.

Previous studies have shown that the host response may vary depending on the viability of the C. albicans [47-49]. We therefore compared the host FGF-2 response from endothelial cells challenged with both viable and nonviable hyphae. The increase in FGF-2 response was specific to live/viable hyphae (Figure 2). Fungal invasion of host cells is a hallmark of C. albicans infection, and Als3 is a key mediator of C. albicans invasion of epithelium and endothelium [33]. Our findings suggest that the invasins (and definitely Als3) are not responsible for inducing the host FGF-2 response (Figure S4). 
Secreted aspartyl proteases are virulence factors of $C$. albicans which are essential for degradation of host proteins and promote C. albicans invasion/penetration of epithelial cells [50]. However, we found that the Saps subfamilies 1-3 and 4-6 are also not involved in inducing the host FGF-2 response (Figure S5). Based on these findings (Figure 2, Figures S4 and S5), we hypothesized that a hypha-specific factor produced by C. albicans - after or during invasion-is involved in eliciting the FGF-2 response.

Candidalysin is a C. albicans hypha-specific toxin encoded by ECE1 [30]. Although the ece1 mutant strains can still form hyphae and invade the host epithelium, studies have shown that these mutants fail to cause epithelial cell damage and activate pro-inflammatory signaling (danger) pathways in oropharyngeal and vulvovaginal candidiasis [30,51,52]. Studies on A. fumigatus show that it produces a toxin (gliotoxin) that regulates host angiogenesis [53]. This raises the possibility that toxins from other fungal systems can also potentially regulate the host FGF-2 response. Indeed, as the results in Figure 3 show, C. albicans induces FGF-2 secretion only when it can produce functional Candidalysin toxin. However, when spent medium from C. albicans hyphal cultures was added to HUVECs, we did not observe a significant change in FGF-2 secretion (Figure S6). It is possible that hyphae create an "invasion pocket" in the endothelial cell which allows for elevated microenvironmental concentrations of Candidalysin. Our results are consistent with the recent observation that epithelial cells were damaged when challenged with $C$. albicans hyphae; however, they were not damaged when challenged with the spent culture medium (discussed in [35]). Nevertheless, our results strongly support the assertion that Candidalysin is primarily responsible for eliciting the host FGF-2 response. While prior studies have been dedicated to elucidating the relationship between Candidalysin and host epithelial responses, not much was known about the regulation of endothelial cell responses by Candidalysin. Here we provide the earliest evidence that Candidalysin also plays a role in regulating/mediating endothelial cell responses. More studies will be required to determine whether Candidalysin also plays a role in any other endothelial cell responses.

What is the consequence of the induction of proangiogenic growth factors during C. albicans infections? Previous studies have shown that in microbial infections, host angiogenesis can either enhance host defense mechanisms or contribute to pathogenicity. For example, treatment with FGF-2 improves antifungal drug activity in a murine model of aspergillosis [17]. Also, ribonuclease 5 angiogenin is known to possess microbicidal activity against pathogenic bacteria in the gastrointestinal tract [54]. In contrast, recent findings have demonstrated that tuberculosis bacteria induce granuloma-associated angiogenesis, which contributes to its pathogenesis $[55,56]$. Another study found the formation of capillary buds and blood vessels around C. albicans foci within infected brains and kidneys [18]. Our discovery that the administration of recombinant FGF-2 into mice post-infection with C. albicans significantly increased mortality compared to non-FGF-2-treated animals suggests that angiogenesis mediated by FGF-2 enhances the pathogenicity of $C$. albicans during a disseminated infection.

From the current study, it appears that angiogenesis is harmful to the host in disseminated C. albicans infections; however, the precise mechanism by which angiogenesis enhances the pathogenicity of the fungus remains unclear. Neither blocking of FGF-2 with a neutralization antibody nor addition of recombinant FGF-2 impacts the ability of $C$. albicans to damage host endothelial cells in vitro (Vellanki and Lee, Unpublished data). We also found that addition or neutralization of cytokines such as interleukin-8 (IL-8) by a drug or antibody did not affect the endothelial cell FGF-2 response to C. albicans infections (Vellanki and Lee, Unpublished data) Based on these results, we hypothesize that FGF-2/angiogenesis is a direct response induced by C. albicans to enhance its dissemination into the deeper host tissues, as previously observed in Mycobacterium tuberculosis infections [57]. Our future studies will focus on elucidating the extent to which C. albicans hyphae and Candidalysin contribute to increasing host angiogenesis in the murine systemic candidiasis model by using existing ece1 mutants that make hyphae but do not secrete Candidalysin and, if necessary, by constructing yeast-locked strains that produce the toxin.

The emergence of antifungal drug resistance has limited our ability to treat $C$. albicans infections and often leads to poor clinical outcomes. Thus, the identification of novel therapeutic avenues that 
can be exploited to treat $C$. albicans infections is required. Host-directed therapeutic approaches which enhance the host's ability to fight the infection, rather than targeting the $C$. albicans components, have already been investigated [58]. As FGF-2 secretion/angiogenesis is apparently enhanced during a C. albicans infection, this process could be targeted by inhibiting FGF-2 function. Blocking a host response related to fungal pathogenicity will represent a new paradigm for treating fungal infections as they can be used irrespective of Candida resistance to current antifungals. Moreover, by targeting a host component of the disease process, the risk of the fungus developing a resistant mechanism to overcome this is massively reduced. Systemic Candida infections pose a serious risk with high mortality rates; thus, a new approach to block host FGF-2 functions during systemic infections could be an effective treatment option. There are drugs which inhibit angiogenesis and/or block FGF-2 function [14], and some of them are already approved by the FDA to treat other diseases. A successful demonstration of efficacy of any of these drugs would eliminate the time normally needed for drug development and enable them to be far more rapidly applied to patients with systemic/disseminated candidiasis. Intriguingly, during our preliminary studies, we discovered that $C$. auris-in which Candidalysin has not been identified-also enhanced the secretion of FGF-2 from host cells (Vellanki and Lee, unpublished data). This approach, therefore, could potentially be extended to disseminated infections caused by other Candida species.

Supplementary Materials: The following are available online at http:/ /www.mdpi.com/2309-608X/5/1/22/s1, Figure S1. A comparison of C. albicans efg $1 \Delta / \Delta$ and WT (SC5314) morphology in the presence of host endothelial cells. Figure S2. Comparison of FGF-2 levels/amounts between HUVEC only, medium only, and C. albicans only. Figure S3: Neither doxycycline nor compound 9029936 itself affect the endothelial cell FGF-2 response. Figure S4: Als3 and BCR1-regulated cell wall proteins are not involved in the induction of host FGF-2 secretion. Figure S5: Sap proteins are not linked with the host endothelial FGF-2 response. Figure S6: C. albicans spent medium is not sufficient to induce the host FGF-2 response.

Author Contributions: Conceptualization, S.C.L. and S.V.; methodology, S.C.L. and S.P.S.; software, none.; validation, S.V., E.Y.H. and S.C.L.; formal analysis, S.V. and S.C.L.; investigation, S.V. and E.Y.H.; resources, S.C.L. and S.P.S.; data curation, S.C.L.; writing-original draft preparation, S.V. and S.C.L.; writing-review and editing, S.C.L., S.V., S.P.S and E.Y.H.; visualization, S.V. and S.C.L.; supervision, S.C.L.; project administration, S.C.L., S.V. and E.Y.H.; funding acquisition, S.C.L.

Funding: This work was supported by NIH/NIAID R03 AI119617 and UTSA Research funds to S.C.L.

Acknowledgments: We would like to acknowledge Brian Peters (The University of Tennessee Health Science Center), Duncan Wilson (University of Aberdeen), and Julian Naglik (King's College London) for providing us with Sap and Candidalysin mutant strains and the Candidalysin peptide. We are indebted to Jose Lopez-Ribot, Chiung-Yu Hung, Astrid Cardona, and Ashraf Ibrahim (Harbor-UCLA Medical Center) for valuable discussions. We would also like to thank the UTSA medical mycology and STCIED groups for their critiques.

Conflicts of Interest: The authors declare no conflict of interest. The funders had no role in the design of the study; in the collection, analyses, or interpretation of data; in the writing of the manuscript; or in the decision to publish the results.

\section{References}

1. Brown, G.D.; Denning, D.W.; Gow, N.A.; Levitz, S.M.; Netea, M.G.; White, T.C. Hidden killers: Human fungal infections. Sci. Transl. Med. 2012, 4, 165rv113. [CrossRef] [PubMed]

2. Carpino, N.; Naseem, S.; Frank, D.M.; Konopka, J.B. Modulating host signaling pathways to promote resistance to infection by Candida albicans. Front. Cell Infect. Microbiol. 2017, 7, 481. [CrossRef] [PubMed]

3. Pfaller, M.A.; Diekema, D.J. Epidemiology of invasive candidiasis: A persistent public health problem. Clin. Microbiol. Rev. 2007, 20, 133-163. [CrossRef] [PubMed]

4. Kullberg, B.J.; Arendrup, M.C. Invasive Candidiasis. N. Engl. J. Med. 2015, 373, 1445-1456. [CrossRef] [PubMed]

5. Nett, J.E.; Andes, D.R. Antifungal Agents: Spectrum of activity, pharmacology, and clinical indications. Infect. Dis. Clin. N. Am. 2016, 30, 51-83. [CrossRef] [PubMed]

6. Shapiro, R.S.; Robbins, N.; Cowen, L.E. Regulatory circuitry governing fungal development, drug resistance, and disease. Microbiol. Mol. Biol. Rev. 2011, 75, 213-267. [CrossRef] [PubMed] 
7. Shapiro, R.S.; Uppuluri, P.; Zaas, A.K.; Collins, C.; Senn, H.; Perfect, J.R.; Heitman, J.; Cowen, L.E. Hsp90 orchestrates temperature-dependent Candida albicans morphogenesis via Ras1-PKA signaling. Curr. Biol. 2009, 19, 621-629. [CrossRef] [PubMed]

8. Sanguinetti, M.; Posteraro, B.; Lass-Florl, C. Antifungal drug resistance among Candida species: Mechanisms and clinical impact. Mycoses 2015, 58, 2-13. [CrossRef] [PubMed]

9. Folkman, J.; Klagsbrun, M. Angiogenic factors. Science 1987, 235, 442. [CrossRef] [PubMed]

10. Nishida, N.; Yano, H.; Nishida, T.; Kamura, T.; Kojiro, M. Angiogenesis in cancer. Vasc. Health Risk Manag. 2006, 2, 213-219. [CrossRef] [PubMed]

11. Sato, Y.; Rifkin, D.B. Autocrine activities of basic fibroblast growth factor: Regulation of endothelial cell movement, plasminogen activator synthesis, and DNA synthesis. J. Cell Biol. 1988, 107, 1199-1205. [CrossRef] [PubMed]

12. Seghezzi, G.; Patel, S.; Ren, C.J.; Gualandris, A.; Pintucci, G.; Robbins, E.S.; Shapiro, R.L.; Galloway, A.C.; Rifkin, D.B.; Mignatti, P. Fibroblast Growth Factor-2 (FGF-2) induces Vascular Endothelial Growth Factor (VEGF) expression in the endothelial cells of forming capillaries: An autocrine mechanism contributing to angiogenesis. J. Cell Biol. 1998, 141, 1659. [CrossRef] [PubMed]

13. Pepper, M.S.; Ferrara, N.; Orci, L.; Montesano, R. Potent synergism between vascular endothelial growth factor and basic fibroblast growth factor in the induction of angiogenesis in vitro. Biochem. Biophys. Res. Commun. 1992, 189, 824-831. [CrossRef]

14. Akl, M.R.; Nagpal, P.; Ayoub, N.M.; Tai, B.; Prabhu, S.A.; Capac, C.M.; Gliksman, M.; Goy, A.; Suh, K.S. Molecular and clinical significance of fibroblast growth factor 2 (FGF2 /bFGF) in malignancies of solid and hematological cancers for personalized therapies. Oncotarget 2016, 7, 44735-44762. [CrossRef] [PubMed]

15. Metzner, T.; Bedeir, A.; Held, G.; Peter-Vörösmarty, B.; Ghassemi, S.; Heinzle, C.; Spiegl-Kreinecker, S.; Marian, B.; Holzmann, K.; Grasl-Kraupp, B.; et al. Fibroblast Growth Factor receptors as therapeutic targets in human melanoma: Synergism with BRAF inhibition. J. Investig. Dermatol. 2011, 131, 2087-2095. [CrossRef] [PubMed]

16. Brady, N.; Chuntova, P.; Bade, L.K.; Schwertfeger, K.L. The FGF/FGFR axis as a therapeutic target in breast cancer. Expert Rev. Endocrinol. Metab. 2013, 8, 391-402. [CrossRef] [PubMed]

17. Ben-Ami, R.; Albert, N.D.; Lewis, R.E.; Kontoyiannis, D.P. Proangiogenic growth factors potentiate in situ angiogenesis and enhance antifungal drug activity in murine invasive aspergillosis. J. Infect. Dis. 2013, 207, 1066-1074. [CrossRef] [PubMed]

18. Ashman, R.B.; Papadimitriou, J.M. Endothelial cell proliferation associated with lesions of murine systemic candidiasis. Infect. Immun. 1994, 62, 5151-5153. [PubMed]

19. Lee, S.C.; Li, A.; Calo, S.; Inoue, M.; Tonthat, N.K.; Bain, J.M.; Louw, J.; Shinohara, M.L.; Erwig, L.P.; Schumacher, M.A.; et al. Calcineurin orchestrates dimorphic transitions, antifungal drug responses and host-pathogen interactions of the pathogenic mucoralean fungus Mucor circinelloides. Mol. Microbiol. 2015, 97, 844-865. [CrossRef] [PubMed]

20. Wang, L.; Pittman, K.J.; Barker, J.R.; Salinas, R.E.; Stanaway, I.B.; Williams, G.D.; Carroll, R.J.; Balmat, T.; Ingham, A.; Gopalakrishnan, A.M.; et al. An atlas of genetic variation linking pathogen-induced cellular traits to human disease. Cell Host Microbe 2018, 24, 308-323.e6. [CrossRef] [PubMed]

21. Barker, K.S.; Park, H.; Phan, Q.T.; Xu, L.; Homayouni, R.; Rogers, P.D.; Filler, S.G. Transcriptome profile of the vascular endothelial cell response to Candida albicans. J. Infect. Dis. 2008, 198, 193-202. [CrossRef] [PubMed]

22. Uppuluri, P.; Pierce, C.G.; Thomas, D.P.; Bubeck, S.S.; Saville, S.P.; Lopez-Ribot, J.L. The transcriptional regulator Nrg1p controls Candida albicans biofilm formation and dispersion. Eukaryot. Cell 2010, 9, 1531-1537. [CrossRef] [PubMed]

23. Romo, J.A.; Pierce, C.G.; Chaturvedi, A.K.; Lazzell, A.L.; McHardy, S.F.; Saville, S.P.; Lopez-Ribot, J.L. Development of anti-virulence approaches for candidiasis via a novel series of small-molecule inhibitors of candida albicans filamentation. MBio 2017, 8. [CrossRef] [PubMed]

24. Gillum, A.M.; Tsay, E.Y.; Kirsch, D.R. Isolation of the Candida albicans gene for orotidine-5'-phosphate decarboxylase by complementation of $S$. cerevisiae ura3 and E. coli pyrF mutations. Mol. Gen. Genet. 1984, 198, 179-182. [CrossRef] [PubMed]

25. Ramage, G.; VandeWalle, K.; Lopez-Ribot, J.L.; Wickes, B.L. The filamentation pathway controlled by the Efg1 regulator protein is required for normal biofilm formation and development in Candida albicans. FEMS Microbiol. Lett. 2002, 214, 95-100. [CrossRef] [PubMed] 
26. Saville, S.P.; Lazzell, A.L.; Monteagudo, C.; Lopez-Ribot, J.L. Engineered control of cell morphology in vivo reveals distinct roles for yeast and filamentous forms of Candida albicans during infection. Eukaryot. Cell 2003, 2, 1053-1060. [CrossRef] [PubMed]

27. Noble, S.M.; Johnson, A.D. Strains and strategies for large-scale gene deletion studies of the diploid human fungal pathogen Candida albicans. Eukaryot. Cell 2005, 4, 298-309. [CrossRef] [PubMed]

28. Cleary, I.A.; Reinhard, S.M.; Miller, C.L.; Murdoch, C.; Thornhill, M.H.; Lazzell, A.L.; Monteagudo, C.; Thomas, D.P.; Saville, S.P. Candida albicans adhesin Als3p is dispensable for virulence in the mouse model of disseminated candidiasis. Microbiology 2011, 157, 1806-1815. [CrossRef] [PubMed]

29. Homann, O.R.; Dea, J.; Noble, S.M.; Johnson, A.D. A phenotypic profile of the Candida albicans regulatory network. PLoS Genet. 2009, 5, e1000783. [CrossRef] [PubMed]

30. Moyes, D.L.; Wilson, D.; Richardson, J.P.; Mogavero, S.; Tang, S.X.; Wernecke, J.; Höfs, S.; Gratacap, R.L.; Robbins, J.; Runglall, M.; et al. Candidalysin is a fungal peptide toxin critical for mucosal infection. Nature 2016, 532, 64. [CrossRef] [PubMed]

31. Lermann, U.; Morschhauser, J. Secreted aspartic proteases are not required for invasion of reconstituted human epithelia by Candida albicans. Microbiology 2008, 154, 3281-3295. [CrossRef] [PubMed]

32. Quintin, J.; Voigt, J.; van der Voort, R.; Jacobsen, I.D.; Verschueren, I.; Hube, B.; Giamarellos-Bourboulis, E.J.; van der Meer, J.W.; Joosten, L.A.; Kurzai, O.; et al. Differential role of NK cells against Candida albicans infection in immunocompetent or immunocompromised mice. Eur J. Immunol. 2014, 44, 2405-2414. [CrossRef] [PubMed]

33. Liu, Y.; Filler, S.G. Candida albicans Als3, a multifunctional adhesin and invasin. Eukaryot. Cell 2011, 10, 168-173. [CrossRef] [PubMed]

34. Nobile, C.J.; Andes, D.R.; Nett, J.E.; Smith, F.J., Jr.; Yue, F.; Phan, Q.-T.; Edwards, J.E., Jr.; Filler, S.G.; Mitchell, A.P. Critical role of Bcr1-dependent adhesins in C. albicans biofilm formation in vitro and in vivo. PLoS Pathog. 2006, 2, e63. [CrossRef] [PubMed]

35. Richardson, J.P.; Mogavero, S.; Moyes, D.L.; Blagojevic, M.; Krüger, T.; Verma, A.H.; Coleman, B.M.; De La Cruz Diaz, J.; Schulz, D.; Ponde, N.O.; et al. Processing of Candida albicans Ece1p is critical for candidalysin maturation and fungal virulence. mBio 2018, 9, e02178-17. [CrossRef] [PubMed]

36. Grubb, S.E.; Murdoch, C.; Sudbery, P.E.; Saville, S.P.; Lopez-Ribot, J.L.; Thornhill, M.H. Candida albicans-endothelial cell interactions: A key step in the pathogenesis of systemic candidiasis. Infect. Immun. 2008, 76, 4370-4377. [CrossRef] [PubMed]

37. Desai, J.V. Candida albicans Hyphae: From Growth Initiation to Invasion. J. Fungi (Basel) 2018, 4. [CrossRef] [PubMed]

38. Jacobsen, I.D.; Wilson, D.; Wächtler, B.; Brunke, S.; Naglik, J.R.; Hube, B. Candida albicans dimorphism as a therapeutic target. Expert Rev. Anti Infect. Ther. 2012, 10, 85-93. [CrossRef] [PubMed]

39. Gow, N.A.; van de Veerdonk, F.L.; Brown, A.J.; Netea, M.G. Candida albicans morphogenesis and host defence: Discriminating invasion from colonization. Nat. Rev. Microbiol. 2011, 10, 112-122. [CrossRef] [PubMed]

40. da Silva Dantas, A.; Lee, K.K.; Raziunaite, I.; Schaefer, K.; Wagener, J.; Yadav, B.; Gow, N.A. Cell biology of Candida albicans-host interactions. Curr. Opin. Microbiol. 2016, 34, 111-118. [CrossRef] [PubMed]

41. Cao, Y.; Gong, Y.; Liu, L.; Zhou, Y.; Fang, X.; Zhang, C.; Li, Y.; Li, J. The use of human umbilical vein endothelial cells (HUVECs) as an in vitro model to assess the toxicity of nanoparticles to endothelium: A review. J. Appl. Toxicol. 2017, 37, 1359-1369. [CrossRef] [PubMed]

42. Antoine, M.; Wirz, W.; Tag, C.G.; Mavituna, M.; Emans, N.; Korff, T.; Stoldt, V.; Gressner, A.M.; Kiefer, P. Expression pattern of fibroblast growth factors (FGFs), their receptors and antagonists in primary endothelial cells and vascular smooth muscle cells. Growth Factors 2005, 23, 87-95. [CrossRef] [PubMed]

43. Müller, V.; Viemann, D.; Schmidt, M.; Endres, N.; Ludwig, S.; Leverkus, M.; Roth, J.; Goebeler, M. Candida albicans triggers activation of distinct signaling pathways to establish a proinflammatory gene expression program in primary human endothelial cells. J. Immunol. 2007, 179, 8435. [CrossRef] [PubMed]

44. Wilson, D.; Mayer, F.L.; Miramon, P.; Citiulo, F.; Slesiona, S.; Jacobsen, I.D.; Hube, B. Distinct roles of Candida albicans-specific genes in host-pathogen interactions. Eukaryot. Cell 2014, 13, 977-989. [CrossRef] [PubMed]

45. Orozco, A.S.; Zhou, X.; Filler, S.G. Mechanisms of the proinflammatory response of endothelial cells to Candida albicans infection. Infect. Immun. 2000, 68, 1134-1141. [CrossRef] [PubMed]

46. Phan, Q.T.; Belanger, P.H.; Filler, S.G. Role of hyphal formation in interactions of Candida albicans with endothelial cells. Infect. Immun. 2000, 68, 3485-3490. [CrossRef] [PubMed] 
47. Gow, N.A.; Netea, M.G.; Munro, C.A.; Ferwerda, G.; Bates, S.; Mora-Montes, H.M.; Walker, L.; Jansen, T.; Jacobs, L.; Tsoni, V.; et al. Immune recognition of Candida albicans beta-glucan by dectin-1. J. Infect. Dis. 2007, 196, 1565-1571. [CrossRef] [PubMed]

48. Rowen, J.L.; Tate, J.M. Heat-Killed Candida albicans elicit more interleukin 8 (IL-8) from human monocytes than live yeast. Pediatr. Res. 1998, 43, 156. [CrossRef]

49. van de Veerdonk, F.L.; Marijnissen, R.J.; Kullberg, B.J.; Koenen, H.J.P.M.; Cheng, S.-C.; Joosten, I.; van den Berg, W.B.; Williams, D.L.; van der Meer, J.W.M.; Joosten, L.A.B.; et al. The macrophage mannose receptor induces IL-17 in Response to Candida albicans. Cell Host Microbe 2009, 5, 329-340. [CrossRef] [PubMed]

50. Kumar, R.; Saraswat, D.; Tati, S.; Edgerton, M. Novel aggregation properties of Candida albicans secreted aspartyl proteinase Sap6 mediate virulence in oral Candidiasis. Infect. Immun. 2015, 83, 2614-2626. [CrossRef] [PubMed]

51. Richardson, J.P.; Willems, H.M.E.; Moyes, D.L.; Shoaie, S.; Barker, K.S.; Tan, S.L.; Palmer, G.E.; Hube, B.; Naglik, J.R.; Peters, B.M. Candidalysin drives epithelial signaling, neutrophil recruitment, and immunopathology at the vaginal mucosa. Infect. Immun. 2017. [CrossRef] [PubMed]

52. Wilson, D.; Naglik, J.R.; Hube, B. The missing link between Candida albicans hyphal morphogenesis and host cell damage. PLoS Pathog. 2016, 12, e1005867. [CrossRef] [PubMed]

53. Ben-Ami, R.; Lewis, R.E.; Leventakos, K.; Kontoyiannis, D.P. Aspergillus fumigatus inhibits angiogenesis through the production of gliotoxin and other secondary metabolites. Blood 2009, 114, 5393-5399. [CrossRef] [PubMed]

54. Ganz, T. Angiogenin: An antimicrobial ribonuclease. Nat. Immunol. 2003, 4, 213. [CrossRef] [PubMed]

55. Datta, M.; Via, L.E.; Kamoun, W.S.; Liu, C.; Chen, W.; Seano, G.; Weiner, D.M.; Schimel, D.; England, K.; Martin, J.D.; et al. Anti-vascular endothelial growth factor treatment normalizes tuberculosis granuloma vasculature and improves small molecule delivery. Proc. Natl. Acad. Sci. USA 2015, 112, 1827-1832. [CrossRef] [PubMed]

56. Oehlers, S.H.; Cronan, M.R.; Scott, N.R.; Thomas, M.I.; Okuda, K.S.; Walton, E.M.; Beerman, R.W.; Crosier, P.S.; Tobin, D.M. Interception of host angiogenic signalling limits mycobacterial growth. Nature 2015, 517, $612-615$. [CrossRef] [PubMed]

57. Polena, H.; Boudou, F.; Tilleul, S.; Dubois-Colas, N.; Lecointe, C.; Rakotosamimanana, N.; Pelizzola, M.; Andriamandimby, S.F.; Raharimanga, V.; Charles, P.; et al. Mycobacterium tuberculosis exploits the formation of new blood vessels for its dissemination. Sci. Rep. 2016, 6, 33162. [CrossRef] [PubMed]

58. Van De Veerdonk, F.L.; Netea, M.G.; Joosten, L.A.; Van Der Meer, J.W.M.; Kullberg, B.J. Novel strategies for the prevention and treatment of Candida infections: The potential of immunotherapy. FEMS Microbiol. Rev. 2010, 34, 1063-1075. [CrossRef] [PubMed]

(C) 2019 by the authors. Licensee MDPI, Basel, Switzerland. This article is an open access article distributed under the terms and conditions of the Creative Commons Attribution (CC BY) license (http://creativecommons.org/licenses/by/4.0/). 